Marquette University

e-Publications@Marquette

7-1-2009

\title{
Enhanced Post-Learning Memory Consolidation is Influenced by Arousal Predisposition and Emotion Regulation but Not By Stimulus Valence or Arousal
}

Kristy A. Nielson

Marquette University, kristy.nielson@marquette.edu

William Lorber

Milwaukee VA Medical Center

NOTICE: this is the author's version of a work that was accepted for publication in Neurobiology of Learning and Memory. Changes resulting from the publishing process, such as peer review, editing, corrections, structural formatting, and other quality control mechanisms may not be reflected in this document. Changes may have been made to this work since it was submitted for publication. A definitive version was subsequently published in Neurobiology of Learning and Memory, Vol. 92, No. 1 (July 2009): 70-79. DOI. (C) 2009 Elsevier. Used with permission. 


\title{
Enhanced post-learning memory consolidation is influenced by arousal predisposition and emotion regulation but not by stimulus valence or arousal
}

\author{
Kristy A. Nielson \\ Department of Psychology, Marquette University \\ Milwaukee, Wisconsin \\ William Lorber \\ Milwaukee VA Medical Center \\ Milwaukee, Wisconsin
}

\begin{abstract}
Emotionally arousing stimuli are more memorable than neutral ones and arousal induced after learning enhances later retrieval. However, there is as yet little study of how stimulus qualities might interact with induced arousal and how individual differences might influence the modulation of memory. Thus, the present study examined the effect of arousal induced after learning on memory for words that varied in both arousal and valence quality, as well as the influence of three individual differences factors that are known to influence arousal response: emotional suppression, emotional reappraisal, and arousal predisposition. Seventy-six adults (57 female) viewed and rated 60 words that normatively ranged from high to low in arousal and valence. Ten minutes later, they viewed a 3-min comedic or neutral video clip. Arousal induced after learning enhanced 1-week delayed memory, spanning the lengthy task without preference for word type or serial position, contrasting with reports of arousal effects interacting with stimulus
\end{abstract}

[Neurobiology of Learning and Memory, Vol 92, No. 1 (July, 2009): pg70-79. DOI. This article is @ Elsevier and permission has been granted for this version to appear in e-Publications@Marquette. Elsevier does not grant permission for this article to be further copied/distributed or hosted elsewhere without the express permission from Elsevier.] 
NOT THE PUBLISHED VERSION; this is the author's final, peer-reviewed manuscript. The published version may be accessed by following the link in the citation at the bottom of the page.

qualities. Importantly, being predisposed to arousal led to greater enhancement of long-term memory modulation, while the use of emotional reappraisal, which reduces arousal responding, inhibited the ability of arousal to induce memory enhancement. Thus, individual differences that influence arousal responding can contribute to or interfere with memory modulation.

Keywords: Memory modulation; Arousal; Reappraisal; Suppression; Individual differences

\section{Introduction}

Emotional and arousing events are generally recollected with greater frequency than similar but neutral events (LaBar \& Cabeza, 2006; McGaugh, 2000, 2004). This is likely an adaptive function, effectively highlighting important stimuli and events to protect and prepare an organism for similar future occasions (McGaugh, 1990). Behavioral studies have investigated factors that might explain this memory advantage, including enhanced attention and elaboration (e.g., Revelle \& Loftus, 1992; Walker, 1958). Although these factors play a role in the memory advantage of emotionally charged information, they are not likely sufficient to explain it (e.g., Bohannon, 1988; Conway et al., 1994; Guy \& Cahill, 1999). Less often discussed are the neural and endogenous hormonal mechanisms that are preferentially engaged in response to arousing or emotive stimuli that can enhance memories even after their formation (cf. Gold \& McGaugh, 1975; McGaugh, 1990, 2000).

Memory consolidation, the memory storage process and the foundation of the emotional memory highlighting process, is the outcome of a complex set of time-dependent neurobiological processes occurring after the initial formation of a memory (McGaugh, 2000; Müller \& Pilzecker, 1900; Nielson \& Powless, 2007; Revelle \& Loftus, 1992; Torras-Garcia, Portell-Cortes, Costa-Miserachs, \& MorgadoBernal, 1997). Indeed, this modulation of memory storage processes can occur quite some time after the original learning experience (cf. Gold \& van Buskirk, 1975; McGaugh, 1966; Nielson \& Powless, 2007; Squire, 1986), enhancing long-term retrieval (e.g., Nielson \& Jensen, 1994; Nielson \& Powless, 2007; Nielson, Radtke, \& Jensen, 1996; Nielson, Yee, \& Erickson, 2005), but often hindering short-term retrieval, likely because the memory consolidation process is believed

[Neurobiology of Learning and Memory, Vol 92, No. 1 (July, 2009): pg70-79. DOI. This article is (C) Elsevier and permission has been granted for this version to appear in e-Publications@Marquette. Elsevier does not grant permission for this article to be further copied/distributed or hosted elsewhere without the express permission from Elsevier.] 
to require perhaps hours or even days (Kleinsmith \& Kaplan, 1963; Revelle \& Loftus, 1992; Torras-Garcia et al., 1997; Walker, 1958).

A variety of substances, including glucose and the adrenal hormones epinephrine, norepinephrine, and under certain circumstances, glucocorticoids such as cortisol, are released into the bloodstream during times of arousal, stress and emotion (Dickerson \& Kemeny, 2004; Gold \& McCarty, 1981; McGaugh, 1990, 2000; Merali, McIntosh, Kent, Michaud, \& Anisman, 1998; Piazza \& Le Moal, 1997). These have been closely linked to memory modulation (e.g., Czech, Nielson, \& Laubmeier, 2000; LaBar \& Cabeza, 2006; McGaugh, 2000; Nielson, Czech, \& Laubmeier, 1999; Nielson \& Jensen, 1994; van Stegeren, Everaerd, Cahill, McGaugh, \& Gooren, 1998). Many animal studies have consistently shown that these substances alter memory in a time-dependent manner and that they generally follow the classic inverted-U dose-response effect (Yerkes \& Dodson, 1908) on memory performance (McGaugh, 1990, 2000). Moreover, these substances indirectly act to modulate the activity of the amygdala, which itself modulates hippocampal memory consolidation processes (Adolphs, Tranel, \& Buchanan, 2005; Canli, Zhao, Brewer, Gabrieli, \& Cahill, 2000; Kensinger \& Corkin, 2004; McGaugh, 2004).

The vast majority of human studies examining the effects of arousal on learning or memory have used inherently emotional materials or interventions before or coincident with the learning task. As such, it is impossible to decipher in these studies whether the effect was on attention, encoding, consolidation or some combination of effects on these phases. However, several recent studies have demonstrated memory modulatory effects in human participants by comparable mechanisms of action as have been shown in rodent studies, using various post-learning treatments including norepinephrine (Southwick et al., 2002), epinephrine (Cahill \& Alkire, 2003), glucose (Manning, Parsons, \& Gold, 1992), nicotine (Colrain, Mangan, Pellett, \& Bates, 1992), and non-invasive treatments such as muscle tension (Nielson \& Jensen, 1994; Nielson et al., 1996), cold pressor stress (Cahill, Gorski, \& Le, 2003) and negative and positive emotional arousal (Nielson \& Bryant, 2005; Nielson \& Powless, 2007; Nielson et al., 2005). Recently, it was also shown using a word-listlearning task that these effects were time-dependent, with long-term retention enhancement when modulation occurred up to 30-min after

[Neurobiology of Learning and Memory, Vol 92, No. 1 (July, 2009): pg70-79. DOI. This article is (C) Elsevier and permission has been granted for this version to appear in e-Publications@Marquette. Elsevier does not grant permission for this article to be further copied/distributed or hosted elsewhere without the express permission from Elsevier.] 
learning but not after 45 minutes (Nielson \& Powless, 2007), and that both negative and positive post-training arousal sources were equally effective to enhance later retention (Liu, Graham, \& Zorawski, 2008; Nielson \& Powless, 2007). Importantly, the studies from our laboratory have intentionally utilized memoranda of neutral valence and arousal to avoid a possible interaction effect of arousal or emotion on encoding processes with the effect of arousal on consolidation. These studies have also instructed participants to intentionally encode the materials, although the long-term retention tests were not announced and manipulation checks showed that the later tests were not expected, thereby reducing the risk of rehearsal contributions to the effect.

In contrast, several studies using both pre-learning (Buchanan \& Lovallo, 2001) and post-learning (Cahill et al., 2003; Liu et al., 2008) treatments that alter stress hormones affected delayed memory retrieval but they did so only for arousing (emotional) stimuli or only for items presented early in a task session (Cahill \& Alkire, 2003). Thus, it has been suggested that arousal induced either before or after learning may only be effective to modulate inherently arousing stimuli (Cahill et al., 2003) or that arousal or novelty at encoding is necessary for post-learning arousal treatments to modulate memory (Cahill \& Alkire, 2003; Okuda, Roozendaal, \& McGaugh, 2004). The latter suggestion was based principally on the idea that unfamiliarity with a task or environment likely leads to greater basal arousal at the start of the task, which can lead to greater memory modulation by treatments after learning (Okuda et al., 2004) or modulation preferably for early items in a task rather than later items (Cahill \& Alkire, 2003).

Interestingly, although arousal rather than valence has consistently been shown to be the factor of effect on memory (Blake, Varnhagen, \& Parent, 2001; Dolcos \& Cabeza, 2002; Kensinger \& Corkin, 2004), these studies differed in terms of recollection advantages based on stimulus valence. In one pre-learning cortisol administration study, the effects were equivalent for both positive and negative stimuli (Buchanan \& Lovallo, 2001), in another that induced stress after learning, the effect was only for negative stimuli (although only negative stimuli were used; Cahill et al., 2003), but in another study that used both negative and humorous video manipulations after learning, the effect was only significant for positive stimuli (although negatively stimuli trended toward significance; Liu et al., 2008).

[Neurobiology of Learning and Memory, Vol 92, No. 1 (July, 2009): pg70-79. DOI. This article is @ Elsevier and permission has been granted for this version to appear in e-Publications@Marquette. Elsevier does not grant permission for this article to be further copied/distributed or hosted elsewhere without the express permission from Elsevier.] 
Moreover, several similar studies have contrastingly demonstrated comparable effects of stress hormone treatments given before learning on both neutral and arousing stimuli (e.g., Abercrombie, Kalin, Thurow, Rosenkranz, \& Davidson, 2003; Lupien et al., 2002; Maheu, Joober, Beaulieu, \& Lupien, 2004). Across these studies, which had greatly differing study designs, the retention interval also varied widely. Thus, it is still rather unclear whether the memory enhancing effects of arousal are selective for emotional material or for early items in a task. Thus, the current study was designed to evaluate whether post-learning induced arousal enhances long-term delayed retention for incidentally learned words, whether it does so selectively for arousing words (positive or negative) versus neutral words, and whether modulation is affected by the serial position of items in list.

Very little study has yet been directed to individual differences that might affect the memory modulation response. The degree to which individuals are susceptible to arousal is a potentially important area of investigation in the context of emotional memory and memory modulation. In addition, the manner in which individuals regulate their emotions can influence physiological, behavioral and cognitive responses to arousal (cf. Gross, 2002). These influences, indeed, cause some emotion regulation strategies to be associated with various clinically relevant phenomena such as post-traumatic stress disorder and generalized anxiety disorder (Gratz \& Roemer, 2004), and might make them foundational influences upon the process of memory modulation. Although there are a number of identified emotion regulation strategies that could be investigated, emotional suppression and reappraisal have recently been studied in the context of their behavioral and cognitive effects (e.g., Richards, 2004; Richards \& Gross, 2006). As such, they are good candidates for investigation in the context of memory modulation.

Arousal predisposition is the tendency or propensity toward arousability (Coren, 1988, 1990). A brief survey developed and validated to measure this propensity has been shown to predict patterns of sleep disruption and insomnia, which is associated with hyperarousal (Coren, 1988), antisocial and criminal behavior, which are associated with underarousal (Coren, 1999), stress response under cognitive load during distraction (Coren \& Aks, 1991), and the degree of autonomic responsiveness to an arousing, white noise stimulus

[Neurobiology of Learning and Memory, Vol 92, No. 1 (July, 2009): pg70-79. DOI. This article is (C) Elsevier and permission has been granted for this version to appear in e-Publications@Marquette. Elsevier does not grant permission for this article to be further copied/distributed or hosted elsewhere without the express permission from Elsevier.] 
(Coren \& Mah, 1993). Thus, because those with higher arousal predisposition also exhibit greater physiological responses to arousal and such responses are fundamental to memory modulation (e.g., McGaugh, 1990, 2000), it might be an important individual differences factor in evaluating responses to memory modulation.

Another fruitful avenue of study involves two opposing emotion regulation strategies that have recently received considerable study reappraisal and suppression. In his process model of emotion regulation, Gross (1998a) distinguished two primary types of emotion regulation strategies that differ based upon when in the course of emotional response they are invoked. First, antecedent-focused emotion regulation strategies occur prior to full activation of emotional response tendencies, and therefore prior to their influence on behavior or physiological responses (Gross \& John, 2003). One example of this is reappraisal, the interpretation of a potentially emotion-eliciting situation in different (e.g., non-emotional) terms (Gross \& John, 2003). In contrast, response-focused emotion regulation strategies occur after the response tendencies elicited by an emotional situation have already begun (Gross \& John, 2003). Suppression, as defined by Gross and colleagues, involves inhibiting the behavioral expression of emotion, is a more commonly studied response-focused ER strategy (Gross, 1998b).

Studies examining suppression in emotive situations have consistently demonstrated decreased outward emotional expression without differences in self-reported negative affect, increased sympathetic nervous system response (Egloff, Schmukle, Burns, \& Schwerdtfeger, 2006; Gross \& John, 2003; Gross \& Levenson, 1993, 1997; Richards \& Gross, 2000), and increased amygdala activation (Goldin, McRae, Ramel, \& Gross, 2008; Ochsner et al., 2004). In contrast, studies of reappraisal have demonstrated successful reduction of emotion expression along with decreased negative affect, non-significant reductions in physiological response (Egloff et al., 2006; Gross, 1998a; Gross \& John, 2003; Richards \& Gross, 2000), and reduced amygdala activation (Goldin et al., 2008; Ochsner et al., 2004).

Memory has been only occasionally studied with respect to emotion regulation. Such studies have demonstrated that suppression

[Neurobiology of Learning and Memory, Vol 92, No. 1 (July, 2009): pg70-79. DOI. This article is (C) Elsevier and permission has been granted for this version to appear in e-Publications@Marquette. Elsevier does not grant permission for this article to be further copied/distributed or hosted elsewhere without the express permission from Elsevier.] 
is associated with reduced retrieval (Bonanno, Papa, Lalande, Westphal, \& Coifman, 2004; Egloff et al., 2006; Richards \& Gross, $1999,2000,2006)$, while reappraisal is associated with unaltered (Egloff et al., 2006; Richards \& Gross, 2000) or with enhanced retrieval (Dillon, Ritchey, Johnson, \& LaBar, 2007; Richards \& Gross, 2000). However, these studies all used very short-term retention tests (10 min; Dillon et al., used $1 \mathrm{~h}$ ). As discussed previously, in arousing conditions, retrieval is frequently impaired when tested soon after learning (Kleinsmith \& Kaplan, 1963; Revelle \& Loftus, 1992; TorrasGarcia et al., 1997), but enhanced when tested much later (e.g., Nielson \& Jensen, 1994; Nielson \& Powless, 2007; Nielson et al., $1996,2005)$. Thus, a truer test of memory retention can be performed when memory is tested hours or days later, when acute arousal has dissipated and consolidation has had time to occur.

Indeed, we recently investigated memory relative to suppression and reappraisal, demonstrating that the retrieval of positively and negatively arousing words was unaffected by suppression and reduced by reappraisal after a 1-week delay (Nielson, Lorber \& Riederer, submitted for publication). The discrepancy between our study and past studies is likely due to (1) the time required for memory consolidation to occur, which can cause arousal to negatively affect immediate retention but enhance delayed retention (Kleinsmith \& Kaplan, 1963; Revelle \& Loftus, 1992; Torras-Garcia et al., 1997; Walker, 1958) and (2) the precise role of the physiological response to arousal on memory consolidation, in part via the amygdala (cf. McGaugh, 2000, 2004). That is, because suppression is associated with increased physiological arousal response and amygdala activation during a learning task, suppression may impair short-term retrieval, but it could result in unimpaired or even enhanced long-term retrieval due to arousal-induced memory modulation. In contrast, because reappraisal is associated with dampened arousal and amygdala activation during a learning task, reappraisal may not affect shortterm retrieval, but it could result in negative effects on memory consolidation. While our previous study supported both of these hypotheses, modulation of memory consolidation was studied only via inherently arousing stimuli. The present study utilized a post-learning memory modulation paradigm together with those stimuli to more directly assess the effects of individual differences in emotion regulation on memory modulation.

[Neurobiology of Learning and Memory, Vol 92, No. 1 (July, 2009): pg70-79. DOI. This article is @ Elsevier and permission has been granted for this version to appear in e-Publications@Marquette. Elsevier does not grant permission for this article to be further copied/distributed or hosted elsewhere without the express permission from Elsevier.] 
Therefore, the current study employed a word-rating task, utilizing both negative and positive, high and low-moderate arousing words. Participants rated the words for pleasantness and arousal, but were not instructed to remember them. An unannounced retention test was then administered 1-week after the initial rating task. Based on previous findings demonstrating that arousal induced shortly after learning enhances delayed retrieval for neutral words (e.g., Nielson \& Jensen, 1994; Nielson \& Powless, 2007; Nielson et al., 1996, 2005), and the mixed literature regarding interaction effects of induced arousal with arousing stimuli, it was hypothesized that arousal induced after learning would comparably enhance delayed retention for neutral and emotional words. Furthermore, based on the utility of arousal predisposition measures to discern those more susceptible to arousal response, it was hypothesized those more predisposed to arousal would demonstrate greater memory modulation effects than those less predisposed. Finally, based on our previous study of emotional suppression and reappraisal, it was hypothesized that suppression would not significantly influence memory modulation, while reappraisal would reduce memory modulation by arousal.

\section{Materials and methods}

\subsection{Participants}

Seventy-six undergraduate students ( 57 females, 19 males; mean age $=18.71, S D=0.11$ ) volunteered for this study and each received course credit for their participation. All of the procedures used were approved by the Institutional Review Board. Each of the 76 participants was randomly assigned to either the control or arousal experimental group in counterbalanced order as they entered the room. This resulted in 39 participants in the arousal group and 37 participants in the control group. Testing was done in small groups of 7-15 participants each.

\subsection{Materials}

\subsubsection{Word-rating task and recognition test}

Sixty words were chosen from the Affective Norms for English Words database (ANEW; Bradley \& Lang, 1999) for the current study. ANEW provides normative ratings (on a 9-point Likert-type scale) for

[Neurobiology of Learning and Memory, Vol 92, No. 1 (July, 2009): pg70-79. DOI. This article is (C) Elsevier and permission has been granted for this version to appear in e-Publications@Marquette. Elsevier does not grant permission for this article to be further copied/distributed or hosted elsewhere without the express permission from Elsevier.] 
valence (pleasant/not pleasant), arousal (excited/calm) and dominance (in control/controlled) ratings more than 1000 common English words. Fifteen words were chosen based on their normative ratings to reflect each of the four theoretical "quadrants" crossing the arousal $(A)$ and valence $(V)$ dimensions (set mean ( \pm SD)): (1) low arousal/negative valence ("weary"), $A=3.71$ (.55), $V=2.84$ (.67); (2) high arousal/negative valence ("slaughter"), $A=7.20$ (.51), $V=1.99$ (.33); (3) low arousal/positive valence ("sunset"), $A=3.44(.56), V=7.45$ (.31); and (4) high arousal/positive valence ("thrill"), $A=7.03$ (.59), $V=8.17$ (.36).

The words were presented in a quasi-randomized order designed to distribute words from the four quadrants equally throughout the list. The words were presented in white lettering on a blue background by PowerPoint, with each word presented for six seconds followed by a ten second blank screen to allow for ratings. The slide number was presented in a small font in the right bottom corner of each slide to assist with place-keeping on the rating forms. A sound ("camera shutter") was activated as each new word was displayed to alert participants to the new stimulus. Participants were asked to silently read each word and then rate their response to it on valence, arousal and dominance dimensions; no instructions were given to remember the words or to suggest that memory would be assessed. Dominance ratings were not analyzed for this study.

The recognition test consisted of 140 words: the 60 list items and 80 distracter words, 20 from each quadrant using the same criteria used for the target list, presented in 5 columns of 28 words each. The normative values of each distracter set were (set mean ( $(\mathrm{SD})$ ): (1) $V=3.07$ (.62), $A=3.91$ (.31); (2) $V=2.07$ (.30), $A=6.91(.46) ;(3) V=7.29(.31), A=4.05(.20)$; and (4) $V=8.0(.35), A=7.03$ (.36). Participants were instructed to mark each word as "new" (not before seen in the study) or "old" (present in the rating task the week earlier). Scores were corrected for guessing using the following formula: corrected recognition $=(1-\mathrm{ER}) *(\%$ Hits $)$, where $\%$ Hits $=$ Hits $/ 60$ and error rate $(E R)=$ proportion of false alarms $(F A / 80)$.

\subsubsection{Arousal manipulation}

[Neurobiology of Learning and Memory, Vol 92, No. 1 (July, 2009): pg70-79. DOI. This article is (C Elsevier and permission has been granted for this version to appear in e-Publications@Marquette. Elsevier does not grant permission for this article to be further copied/distributed or hosted elsewhere without the express permission from Elsevier.] 
NOT THE PUBLISHED VERSION; this is the author's final, peer-reviewed manuscript. The published version may be accessed by following the link in the citation at the bottom of the page.

Arousal was induced using a 3-min, live-action video comedy skit ("Saturday Night Live's," Jingleheimer Junction), which was demonstrated to be effective for post-learning memory modulation in a previous study (Nielson \& Powless, 2007). Control participants viewed a 3-min, live-action video segment of a Public Broadcasting Service documentary.

\subsubsection{Subjective mood and arousal measures}

Subjective state was measured on five occasions from the beginning to the end of the session using a Likert-type scale for arousal, "Please rate how much arousal you are feeling at this moment" and mood, "Please rate your mood at this moment." Both scales ranged from 1 (extremely negative (mood)/low (arousal)) to 9 (extremely positive (mood)/high (arousal)).

\subsubsection{Individual differences measures}

The emotion regulation questionnaire (ERQ; Gross \& John, 2003) is a 10 -item self-report measure that was used to classify participants based on their habitual use of the emotion regulation strategies, suppression and reappraisal. It uses a 7-point scale ranging from strongly disagree (1) to strongly agree (7). The four suppression items ask participants to rate the extent to which they typically try to inhibit their emotion-expressive behavior (e.g., "I keep my emotions to myself"), while the six reappraisal items ask participants to rate the extent to which they typically try to think about situations differently in order to change how they feel (e.g., "When I'm faced with a stressful situation, I make myself think about it in a way that helps me stay calm"). The ERQ has high internal reliability and convergent and discriminant validity, and both subscales have demonstrated internal reliability (suppression, .68-.76; reappraisal .75-.82; Gross \& John, 2003). The median score of the sample was used to split the participants into low and high reappraisal (median $=30$; range $=14-$ $41 ; n=32$ low, 44 high) and suppression groups (median $=13$; range $=4-26 ; n=31$ low, 45 high). As these scores were determined after testing, the experimental groups were not equally distributed across reappraisal and suppression, but effect sizes in the resulting analyses suggest that the cell sizes were sufficient (reappraisal: control group, 13 low, 24 high; arousal group, 19 low, 20 high;

[Neurobiology of Learning and Memory, Vol 92, No. 1 (July, 2009): pg70-79. DOI. This article is @ Elsevier and permission has been granted for this version to appear in e-Publications@Marquette. Elsevier does not grant permission for this article to be further copied/distributed or hosted elsewhere without the express permission from Elsevier.] 
suppression: control group, 19 low, 18 high; arousal group, 12 low, 27 high).

The arousal predisposition scale (APS) is a normed, 12-item self-report instrument designed to measure an individual's susceptibility to arousal, viewed as a trait or a predisposition (Coren, $1988,1990)$. It is measured on a 5-point scale from never (1) to always (5), with possible score ranges from 12 to 60 and good internal consistency (.84). The normative mean is approximately 36 , but females tend to have a higher score range than males (Coren, 1990). The APS predicts patterns of sleep disruption $(r=.45)$, stress under cognitive load (Coren \& Aks, 1991), and individual differences in autonomic arousal (Coren \& Mah, 1993). The median score of the sample (median $=35$; range $=18-52$ ) was used to split the participants into low $(n=37)$ and high $(n=39)$ arousal predisposition groups. Although scored after testing, the resulting distribution of APS groupings was comparable across experimental groups (control group: 21 low, 16 high; arousal group: 19 low, 20 high).

Notably, these three individual differences measures were not correlated across subjects. Reappraisal and suppression are theoretically uncorrelated, and the data supported their independence $(r=-.077, p=.51)$. The APS did not correlate significantly with either reappraisal $(r=-.081, p=.49)$ or suppression $(r=.061, p=.60)$.

\subsection{Procedure}

The purpose of the study (i.e., to measure participants responses to various words, some pleasant, some unpleasant) was explained and informed consent was obtained. A demographic survey was then administered, followed by the first mood/arousal survey. The word-rating task was then administered. This was followed by a second mood/arousal survey. Afterward, participants completed a packet of multiple surveys for a 10-min interval. The packet included the APS and the ERQ, with the remaining measures serving as unscored filler measures (distracting from the study purpose), and to interject a 10-min delay prior to arousal manipulation, which was shown in a recent study to be advantageous for memory modulation (Nielson \& Powless, 2007). This was followed by the third

[Neurobiology of Learning and Memory, Vol 92, No. 1 (July, 2009): pg70-79. DOI. This article is (C) Elsevier and permission has been granted for this version to appear in e-Publications@Marquette. Elsevier does not grant permission for this article to be further copied/distributed or hosted elsewhere without the express permission from Elsevier.] 
mood/arousal survey. Participants then viewed either the arousal or control video clip, depending on group assignment. A final mood/arousal survey completed the session. Participants were thanked, reminded of their appointment for a similar task the following week and dismissed. Upon returning 1-week later, an unannounced recognition test for the words in the rating task the previous week was administered. Participants were then debriefed and dismissed. Analyses utilized mixed-model ANOVA with a $p<.05$ threshold for significance.

\section{Results}

\subsection{Word ratings}

A two arousal group by four quadrant mixed ANOVA for arousal and valence ratings of the words, measured prior to any experimental manipulation, demonstrated the expected ANEW-norms pattern and they did not differ by or interact with experimental group. Specifically, the main effects for quadrant for each rating were each significant (valence: $F(3,222)=1051.30, p<.001, \eta^{2}=.934$;

arousal: $\left.F(3,219)=71.13, p<.001, \eta^{2}=.493\right)$, while there were no significant Group main effects at this baseline stage

(valence: $F(1,74)=0.14, p=.71, \eta^{2}=.002$;

arousal: $\left.F(1,73)=.001, p=.98, \eta^{2}=.00\right)$ or quadrant by group interactions (valence: $F(3,222)=0.71, p=.55, \eta^{2}=.01$; arousal: $\left.F(3,219)=0.87, p=.46, \eta^{2}=.012\right)$.

Analyses were then performed alternately adding each individual differences variable. The effects in the primary analysis were not significantly altered by these additions. There were no significant effects involving valence for any of the factors: reappraisal (main effect: $F(1,72)=0.53, p=.47, \eta^{2}=.007$; quadrant $\times$ reappraisal: $F(3,216)=0.97, p=.41, \eta^{2}=.013$; quadrant $\times$ group $\times$ reappraisal: $F(3,216)=0.65, p=.59, \eta^{2}=.009$; group $\times$ reappraisal: $\left.F(1,72)=1.15, p=.29, \eta^{2}=.016\right)$; suppression (main effect: $F(1,72)=0.31, p=.58, \eta^{2}=.004$; quadrant $\times$ suppression: $F(3,216)=0.16, p=.93, \eta^{2}=.02$; quadrant $\times$ group $\times$ suppression: $F(3,216)=1.30, p=.28, \eta^{2}=.018$ ; group $\times$ suppression: $\left.F(1,72)=1.24, p=.27, \eta^{2}=.017\right)$; or APS (main effect: $F(1,72)=0.88, p=.35, \eta^{2}=.012$;

[Neurobiology of Learning and Memory, Vol 92, No. 1 (July, 2009): pg70-79. DOI. This article is @ Elsevier and permission has been granted for this version to appear in e-Publications@Marquette. Elsevier does not grant permission for this article to be further copied/distributed or hosted elsewhere without the express permission from Elsevier.] 
quadrant $\times$ APS: $F(3,216)=0.07, p=.98, \eta^{2}=.001$;

quadrant $\times$ group $\times$ APS: $F(3,216)=0.73, p=.54, \eta^{2}=.010$;

Group $\times$ APS: $\left.F(1,72)=0.003, p=.96, \eta^{2}=.000\right)$.

In contrast, there were significant effects or trends for each of the individual differences variables with respect to arousal ratings. First, those most highly predisposed to arousal rated words as more arousing than did those with low APS scores $\left(F(1,71)=4.02, p=049, \eta^{2}=.054\right)$; there were no significant interactions (quadrant $\times$ APS: $F(3,213)=0.84, p=.97, \eta^{2}=.001$; quadrant $\times$ group $\times$ APS: $F(3,213)=1.86, p=.14, \eta^{2}=.025$; group $\times$ APS: $\left.F(1,71)=0.09, p=.77, \eta^{2}=.001\right)$. Second, there was a significant interaction between word quadrant and suppression, showing that high suppressors had significantly higher arousal ratings of negative high arousal words, but significantly lower ratings of positive low arousal words than low suppressors (quadrant $\times$ suppression: $F(3,213)=3.27, p=.02, \eta^{2}=.044$; main effect: $F(1,71)=0.29, p=.59, \eta^{2}=.004$;

quadrant $\times$ group $\times$ suppression: $F(3,213)=0.72, p=.98, \eta^{2}=.001$ ; group $\times$ suppression: $\left.F(1,71)=0.84, p=.36, \eta^{2}=.012\right)$. Finally, there was also a non-significant trend for an interaction between word quadrant and reappraisal, showing that high reappraisal participants had lower ratings of negative high arousal words, but higher ratings of positive low arousal words than low reappraisal participants (quadrant $\times$ reappraisal: $F(3,213)=2.54, p=.057, \eta^{2}=.035$; main effect: $F(1,71)=0.08, p=.78, \eta^{2}=.001$; quadrant $\times$ group $\times$ reappraisal: $F(3,213)=0.21, p=.89, \eta^{2}=.003$; group $\times$ reappraisal: $\left.F(1,71)=0.03, p=.87, \eta^{2}=.000\right)$.

\subsection{Mood and arousal state}

A two arousal group by five measures mixed ANOVA for selfreported mood demonstrated a significant interaction of measures by group, whereby the groups were equivalent in ratings except when measured immediately after the video manipulation, when the comedy group rated their mood as significantly more positive than did the control group (measures: $F(4,292)=9.51, p<.001, \eta^{2}=.12$; group: $F(1,73)=1.20, p=.28, \eta^{2}=.02$; measures by group: $F(4,292)=14.5, p<.001, \eta^{2}=.17 ; 1$-way measure $4 \times$ group: $F(1,74)=31.81, p<.001)$. These results are shown in Fig. 1.

[Neurobiology of Learning and Memory, Vol 92, No. 1 (July, 2009): pg70-79. DOI. This article is (C) Elsevier and permission has been granted for this version to appear in e-Publications@Marquette. Elsevier does not grant permission for this article to be further copied/distributed or hosted elsewhere without the express permission from Elsevier.] 
NOT THE PUBLISHED VERSION; this is the author's final, peer-reviewed manuscript. The published version may be accessed by following the link in the citation at the bottom of the page.
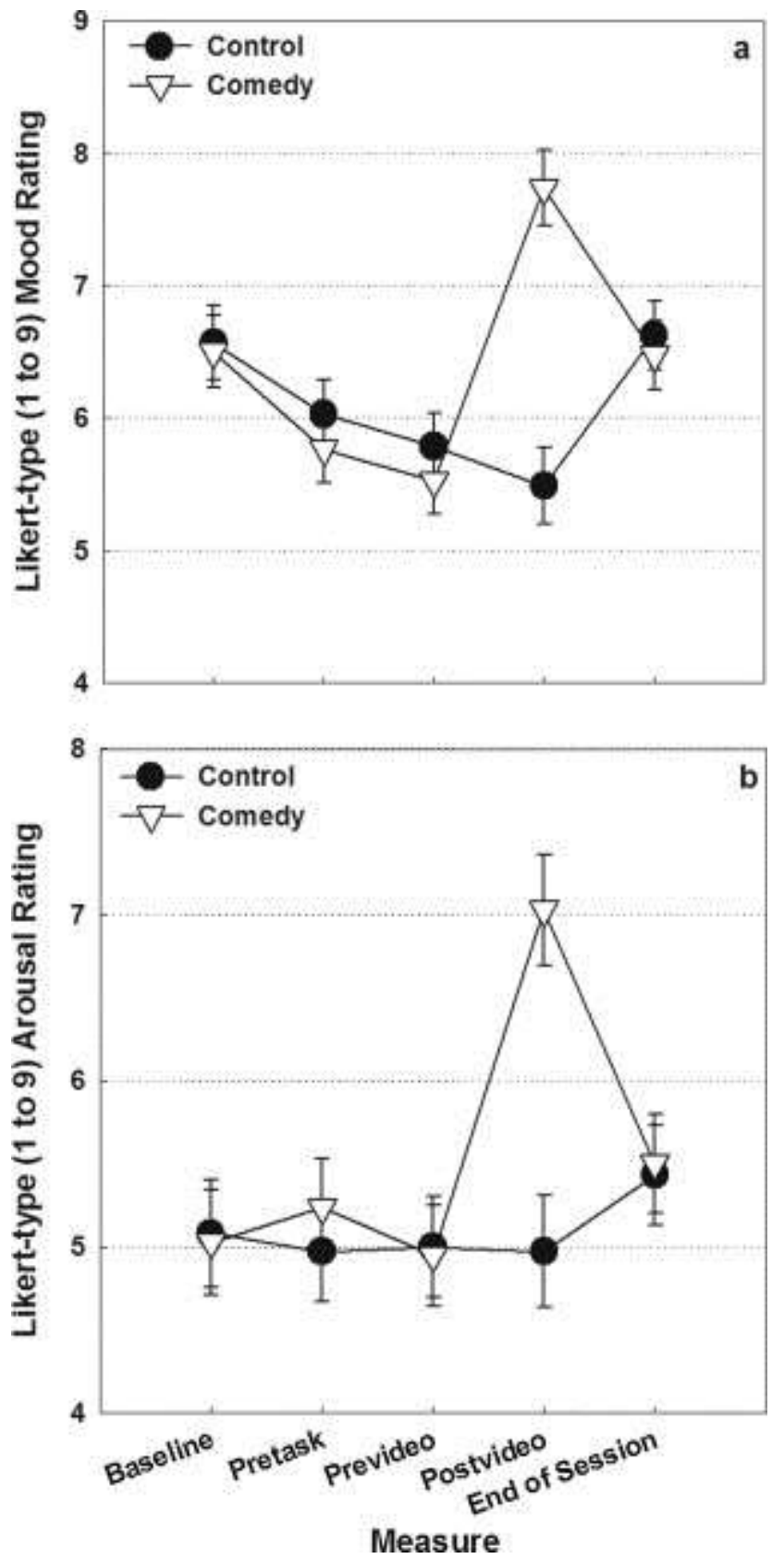

Fig. 1. Self-reported mood (a) and arousal (b) ratings (mean \pm SEM) measured at five times during the task demonstrated that the experimental groups were equivalent in ratings except when measured immediately after the video manipulation, when the comedy group rated their mood as significantly more positive and their arousal as significantly greater than did the control group.

The addition of individual differences measures did not alter the primary effects of group and measures on mood. However, they did add some effects. Specifically, there was a significant three-way interaction with APS, whereby high APS participants exhibited lesser

[Neurobiology of Learning and Memory, Vol 92, No. 1 (July, 2009): pg70-79. DOI. This article is (C) Elsevier and permission has been granted for this version to appear in e-Publications@Marquette. Elsevier does not grant permission for this article to be further copied/distributed or hosted elsewhere without the express permission from Elsevier.] 
extremes of mood in both conditions than the low APS participants $\left(\right.$ measures $\times$ group $\times$ APS: $F(4,284)=2.49, p=.044, \eta^{2}=.034$; group $\times$ APS: $F(1,71)=0.15, p=.70, \eta^{2}=.002$; measures $\times$ APS: $F(4,284)=0.17, p=.95, \eta^{2}=.002$; arousal: $\left.F(1,71)=0.14, p=.72, \eta^{2}=.002\right)$. There was also a significant main effect of suppression

$\left(F(1,71)=4.61, p=.035, \eta^{2}=.061\right)$ with a trend toward a threeway interaction, such that high suppression led to poorer overall mood, though after the arousal induction, there was little difference between suppression groups in the comedy condition, while the mood difference persisted in the control condition (measures $\times$ group $\times$ suppression: $F(4,284)=2.21, p=.068, \eta^{2}=.0$ 30 ; measures $\times$ suppression: $F(4,284)=0.76, p=.55, \eta^{2}=.011$; group $\times$ suppression: $\left.F(1,71)=0.71, p=.40, \eta^{2}=.010\right)$. Finally, there were no significant effects of reappraisal on mood (main effect: $F(1,71)=0.17, p=.90, \eta^{2}=.000$; measures $\times$ reappraisal: $F(4,284)=1.91, p=.32, \eta^{2}=.017$; measures $\times$ group $\times$ reappraisal: $F(4,284)=.14, p=.97, \eta^{2}=.002$; group $\times$ reappraisal: $\left.F(1,71)=0.41, p=.52, \eta^{2}=.006.\right)$.

A 2 group by 5 measures mixed ANOVA for self-reported arousal also demonstrated a significant interaction of measures by group, whereby the groups were equivalent in ratings except when measured immediately after the video manipulation, when the comedy group rated their arousal as significantly greater than did the control group (measures: $F(4,292)=5.66, p<.001, \eta^{2}=.07$; group: $F(1,73)=2.24, p=.14, \eta^{2}=.03$; measures by group: $F(4,292)=6.4, p<.001, \eta^{2}=.081 ; 1$-way measure $4 \times$ group: $F(1,74)=18.56, p<.001)$. These results are shown in Fig. 1.

The addition of reappraisal did not influence arousal state ratings (main effect: $F(1,71)=0.61, p=.44, \eta^{2}=.008$; measures $\times$ reappraisal: $F(4,284)=0.40, p=.81, \eta^{2}=.006$; measures $\times$ group $\times$ reappraisal: $F(4,284)=0.30, p=.88, \eta^{2}=.004$ ; group $\times$ reappraisal: $\left.F(1,71)=0.33, p=.57, \eta^{2}=.005\right)$. The addition of APS showed only a trend toward greater overall arousal ratings by those highly predisposed to arousal (main effect: $F(1,71)=3.64, p=.06, \eta^{2}=.049$; measures $\times$ APS: $F(4,284)=0.60, p=0.66, \eta^{2}=.008$; 
measures $\times$ group $\times$ APS: $F(4,284)=0.46, p=.77, \eta^{2}=.006$; group $\times$ APS: $\left.F(1,71)=0.24, p=.63, \eta^{2}=.003 ;\right)$. However, the inclusion of suppression in the analysis demonstrated a significant three-way interaction, whereby high suppressors had lower arousal ratings in the control condition than low suppressors, but not in the arousal condition

(measures $\times$ group $\times$ suppression: $F(4,284)=3.16, p=.015, \eta^{2}=.0$ 43; main effect: $F(1,71)=0.53, p=.82, \eta^{2}=.001$; measures $\times$ suppression: $F(4,284)=0.60, p=.67, \eta^{2}=.008$; group $\times$ suppression: $\left.F(1,71)=0.00, p=.99, \eta^{2}=.000\right)$.

\subsection{Recognition memory}

A two arousal group by four quadrant mixed ANOVA was used to analyze recognition memory. A significant quadrant main effect showed that low arousal/negative valence words were less well retained than words from the other categories $\left(F(3,222)=46.09, p<.001, \eta^{2}=.384\right.$; all confirmatory 1-way ANOVAs: all $\left.F \mathrm{~s}(1,74)>68.4, p=.000, \eta^{2}>.48\right)$, and that high arousal/negative valence words were somewhat less well retained than low arousal/positive valence words (contrast $\left.F(1,74)=4.6, p=.035, \eta^{2}=.059\right)$. The other quadrants did not differ from each other $(p s>118)$. A significant group main effect also showed that the comedy group retrieved significantly more words overall than did the neutral group $\left(F(1,74)=13.69, p<.001, \eta^{2}=.156\right)$. These results are shown in Fig. 2. The interaction was not significant $\left(F(3,222)=0.62, p=.60, \eta^{2}=.008\right)$.

[Neurobiology of Learning and Memory, Vol 92, No. 1 (July, 2009): pg70-79. DOI. This article is @ Elsevier and permission has been granted for this version to appear in e-Publications@Marquette. Elsevier does not grant permission for this article to be further copied/distributed or hosted elsewhere without the express permission from Elsevier.] 
NOT THE PUBLISHED VERSION; this is the author's final, peer-reviewed manuscript. The published version may be accessed by following the link in the citation at the bottom of the page.
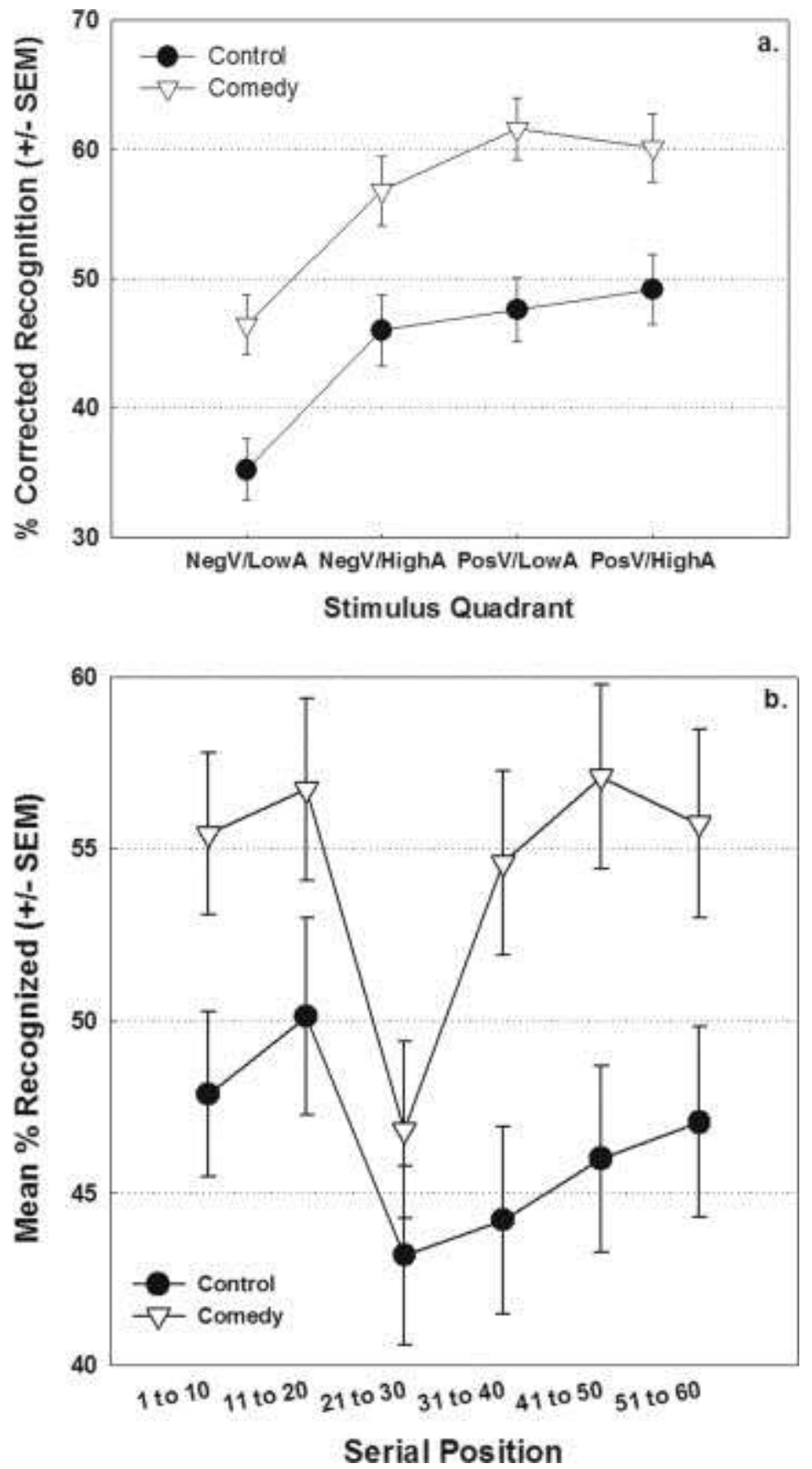

Fig. 2. (a) Corrected recognition memory performance (mean $\pm S E M$ ) is plotted by arousal group and word quadrant. The low arousal/negative valence words were less well retained than words from the other categories, and the Comedy group demonstrated superior retention to the control group in across all quadrants. The quadrant $\times$ group interaction was not significant. (b) Recognition performance (mean \pm SEM) depicted according to the serial position of the words in the list is shown in sets of 10-items each. There was no interaction between arousal group and serial position.

[Neurobiology of Learning and Memory, Vol 92, No. 1 (July, 2009): pg70-79. DOI. This article is @ Elsevier and permission has been granted for this version to appear in e-Publications@Marquette. Elsevier does not grant permission for this article to be further copied/distributed or hosted elsewhere without the express permission from Elsevier.] 
To assess whether post-task arousal effects on retention were influenced by the position of words in the list, successfully recognized items were scored by their serial position in the list in six sets of 10items each. Retention among the sets differed as would be expected $\left(F(5,365)=7.42, p<.001, \eta^{2}=.092\right)$, and tne main effect of group showed better overall performance by the arousal group, consistent with the general analysis $\left(F(1,73)=6.40, p=.014, \eta^{2}=.081\right)$. However, there was no significant interaction of group with serial position set, $\left.F(5,365)=1.58, p=.16, \eta^{2}=.021\right)$. There was greater retention performance for the arousal group in all six sets, with only the third set not differing to a statistically significant degree or trend (group contrasts $p^{\prime}$ s $=.027$ (set 1$), .085$ (set 2), .32 (set 3), .008 (set 4), .005 (set 5), .029 (set 6)). These results are depicted in Fig. 2.

Analyses alternately adding the individual differences measures did not reduce the quadrant or group main effects. A three-way mixed ANOVA evaluating the role of arousal predisposition demonstrated a significant interaction with arousal group on retention, such that those highly predisposed to arousal benefitted the most from arousal induction (see Fig. 3);

group $\times$ APS: $F(1,72)=3.90, p=.05, \eta^{2}=.051$; main effect: $F(1,72)=3.56, p=.06, \eta^{2}=.047$; quadrant $\times$ APS: $F(3,216)=0.69, p=.56, \eta^{2}=.01$; quadrant $\times$ APS $\times$ group: $F(3,216)=0.79, p=.50, \eta^{2}=.01$; quadrant: $F(3,216)=45.84, p<.001, \eta^{2}=.389$; quadrant $\times$ group: $F(3,216)=0.65, p=.59, \eta^{2}=.009$; group: $\left.F(1,72)=14.34, p<.001, \eta^{2}=.166\right)$. 
NOT THE PUBLISHED VERSION; this is the author's final, peer-reviewed manuscript. The published version may be accessed by following the link in the citation at the bottom of the page.

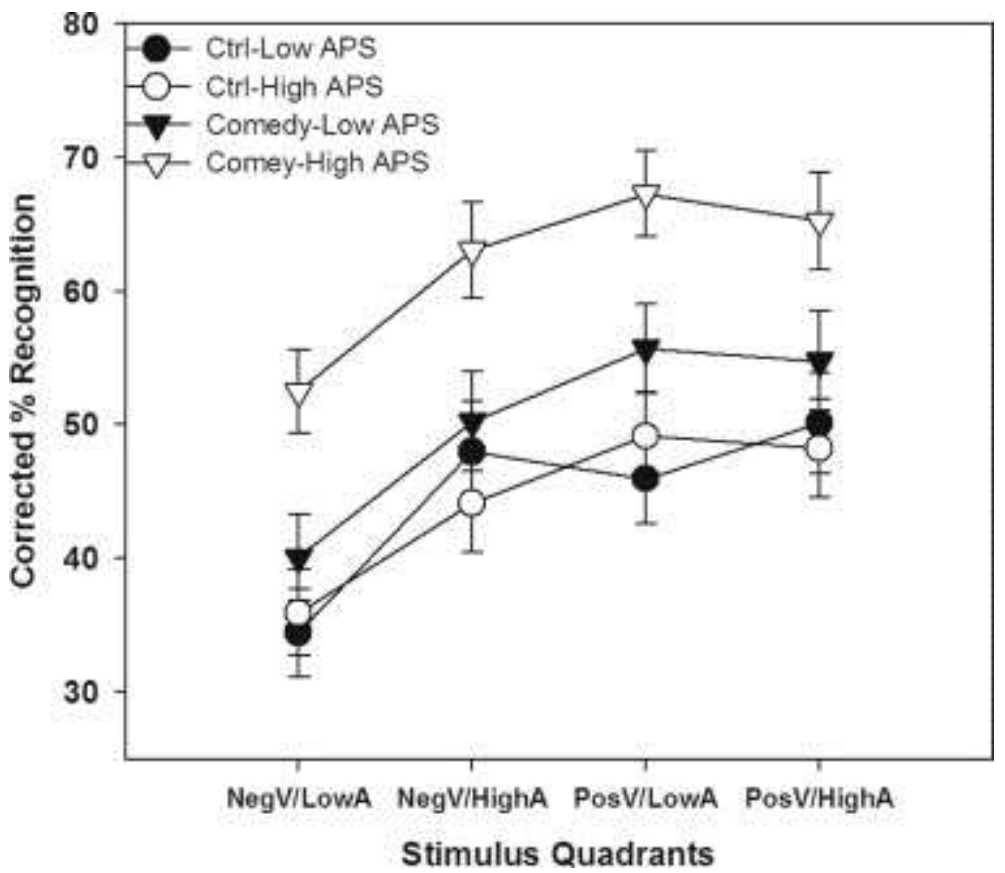

Fig. 3. Corrected recognition memory performance (mean \pm SEM) is plotted by arousal group, arousal predisposition group and word quadrant. There was a significant main effect of arousal predisposition group, such that high predisposition participants retrieved more words than did low predisposition participants. Although the interaction with arousal group was not significant, the main effect of arousal group is also apparent with arousal predisposition, such that the high predisposition participants within the arousal group retrieved the most words.

A three-way mixed ANOVA evaluating the role of emotional suppression demonstrated no significant effects involving suppression (main effect: $F(1,72)=0.46, p=.50, \eta^{2}=.006$; quadrant $\times$ suppression $\times$ group: $F(3,216)=0.34, p=.80, \eta^{2}=.005$ ; quadrant $\times$ suppression: $F(3,216)=0.84, p=.48, \eta^{2}=.011$; group $\times$ suppression: $\left.F(1,72)=0.001, p=.97, \eta^{2}=.00\right)$. However, when considering reappraisal, there was a significant interaction of reappraisal by arousal group on retention such that high reappraiser had less benefit of arousal induction than low reappraisers (see Fig. 4; group $\times$ reappraisal: $F(1,72)=4.30, p=.042, \eta^{2}=.056$; main effect: $F(1,72)=2.07, p=.15, \eta^{2}=.028$; quadrant $\times$ reappraisal $\times$ group: $F(3,216)=2.20, p=.09, \eta^{2}=.03$; quadrant $\times$ reappraisal: $\left.F(3,216)=1.34, p=.26, \eta^{2}=.02\right)$.

[Neurobiology of Learning and Memory, Vol 92, No. 1 (July, 2009): pg70-79. DOI. This article is @ Elsevier and permission has been granted for this version to appear in e-Publications@Marquette. Elsevier does not grant permission for this article to be further copied/distributed or hosted elsewhere without the express permission from Elsevier.] 


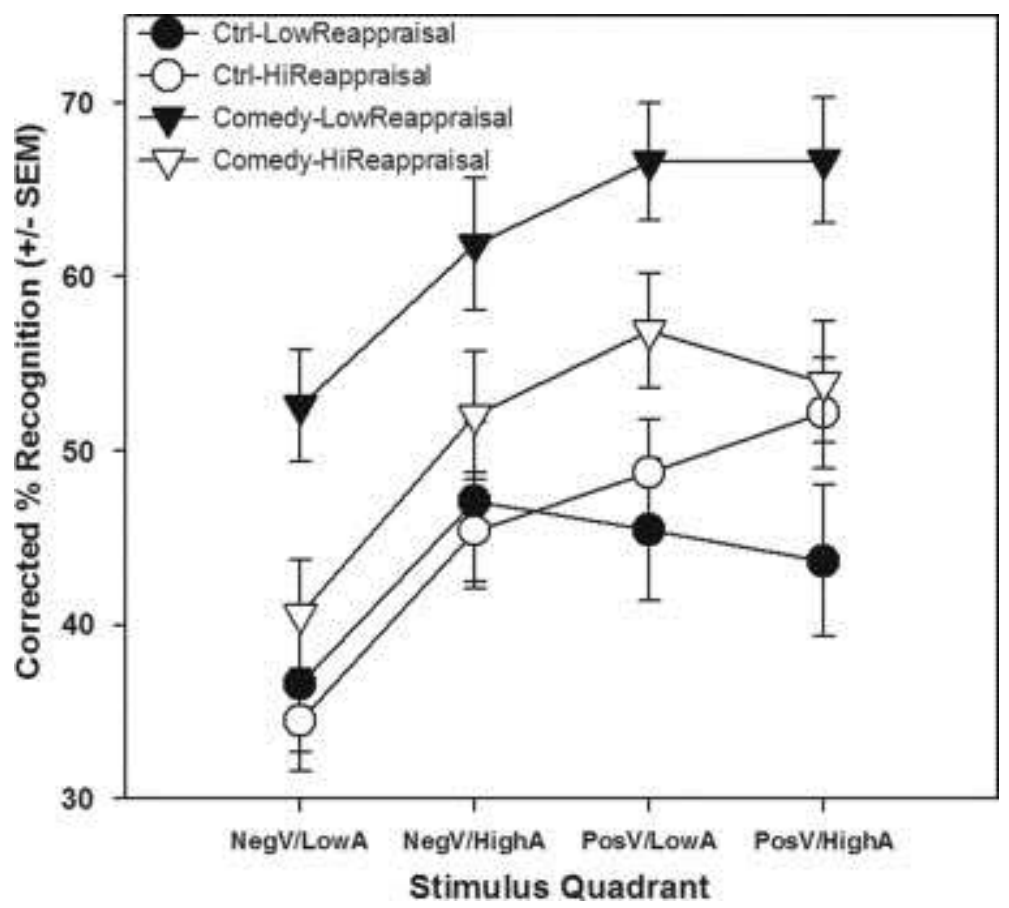

Fig. 4. Corrected recognition memory performance (mean $\pm \mathrm{SEM}$ ) is plotted by arousal group, reappraisal group and word quadrant. The interaction was significant such that within the arousal group, low reappraisers had significantly better retention than high reappraisers, but this difference did not occur within the control group.

\section{Discussion}

The purpose of the current study was to evaluate the effect of post-task arousal on incidental retention for emotionally arousing words, and to evaluate the influence of individual differences on this effect. With respect to the first goal, the results showed that the arousal manipulation was effective to enhance later retrieval. Although word ratings were equivalent between experimental groups (prior to the manipulation) and mood and arousal state ratings were equivalent between groups except immediately following the manipulation, arousal induced after the word-rating task led to enhanced delayed retention of all word categories relative to the control condition. Indeed, the effect was not influenced by the degree of arousal or valence of the words themselves, or by the position of words in the list.

The present results are consistent with a number of recent studies from our laboratory and from others that demonstrated posttraining arousal-induced modulation of memory using neutral stimuli (Colrain et al., 1992; Manning et al., 1992; Nielson \& Bryant, 2005; 
Nielson \& Jensen, 1994; Nielson \& Powless, 2007; Nielson et al., 1996, 2005), including those that specifically employed a pleasant postlearning arousal stimulus (Nielson \& Bryant, 2005; Nielson \& Powless, 2007). Indeed, the current study demonstrated no differences in modulation efficacy based on the serial position of the words in the list. Only the set in the middle of the list, a position that is known to reflect the poorest retrieval (cf. Burgess \& Hitch, 1999; Crowder, 1972), did not differ between arousal groups. These results suggest that a post-learning manipulation can readily affect retention for an entire, rather lengthy task. Thus, the present findings suggest that arousal induced after learning could potentially enhance retention for any type of material. Livingston (1967) proposed such an idea, that hormone response to stress that occurs after learning can modulate memory for any recently acquired information. Our findings are consistent with this proposition.

In contrast, several recent studies found arousal-induced modulation effects on memory that were selective for emotive stimuli when both high and low arousal stimuli were employed, leading to conclusions that arousal affects memory only for arousing stimuli (Buchanan \& Lovallo, 2001; Cahill et al., 2003; Liu et al., 2008). Such an interaction hypothesis is feasible. Epinephrine, corticosteroids and glucose are released as part of the response to emotional and stressful situations, and these substances alter memory consolidation for a variety of tasks when given or induced post-training (cf. McGaugh, 2000). These effects depend on the functional integrity of the betaadrenergic receptors of the basolateral amygdala that modulate hippocampal and striatal activity (Kerfoot, Chattillion, \& Williams, 2008; McGaugh, 2004; Miyashita \& Williams, 2004). Moreover, adrenergic mechanisms play a role in human memory modulation (e.g., Cahill, Prins, Weber, \& McGaugh, 1994; Nielson \& Jensen, 1994; van Stegeren et al., 1998), and stress hormones such as epinephrine and corticosteroids are released in humans in response to both pleasant and aversive stimuli (e.g., Merali et al., 1998; Piazza \& Le Moal, 1997). Furthermore, amydgalar activation has been shown to be greater in response to positive and negative arousing stimuli when compared with neutral stimuli (e.g., Garavan, Pendergrass, Ross, Stein, \& Risinger, 2001; Hamann \& Mao, 2002).

[Neurobiology of Learning and Memory, Vol 92, No. 1 (July, 2009): pg70-79. DOI. This article is (C) Elsevier and permission has been granted for this version to appear in e-Publications@Marquette. Elsevier does not grant permission for this article to be further copied/distributed or hosted elsewhere without the express permission from Elsevier.] 
Thus, the interaction hypothesis would suggest that the endogenous response to inherently arousing or emotional stimuli leads to modulation of memory for these stimuli and as such, this effect would interact with any post-task induced arousal effect to enhance it further (or perhaps to impair it depending on the intensity of the combined responses). However, because memory modulation occurs also with post-training arousal induction in the absence of arousing stimuli, it is reasonable to conclude that the activation of these mechanisms can alter memory for neutral as well as arousing stimuli. Therefore, it is possible that post-training arousal may preferentially enhance arousing stimuli if they are present, but it is not a necessary condition for efficacy (Nielson \& Bryant, 2005).

Importantly, however, the current study was not consistent with the above stated interaction hypothesis. Stimuli systematically chosen to reflect low to high arousal and positive to negative valence were presented in quasi-random order, showing no interaction of the valence or arousal quality of the stimuli with the post-task arousal induction and no relationship to position within the list. Indeed, all categories of stimuli were equally enhanced by $10-$ min delayed posttraining arousal induction. Thus, the present study does not support the conclusion drawn in a few recent studies that arousal induced either before or after learning may only be effective to modulate inherently arousing stimuli (Cahill et al., 2003) or that heightened arousal state early in encoding due to novelty of the task or situation will cause preferential modulation of initial task items over later items (Cahill \& Alkire, 2003; Okuda et al., 2004). Instead, it supports recent findings using post-training arousal following neutral stimuli (Nielson \& Bryant, 2005; Nielson \& Powless, 2007; Nielson et al., 1996, 2005), as well as those of others who used pre-learning (Abercrombie et al., 2003; Lupien et al., 2002; Maheu et al., 2004) or post-learning manipulations (Colrain et al., 1992; Manning et al., 1992) but found memory modulatory effects that were not restricted to emotive materials.

Because our previous studies used only neutral materials and involved intentional learning paradigms, the current study employed both emotive stimuli and incidental learning to provide a more direct comparison with the arousal interaction studies. Thus, it is particularly notable that even with more comparable methodology, the present

[Neurobiology of Learning and Memory, Vol 92, No. 1 (July, 2009): pg70-79. DOI. This article is (C) Elsevier and permission has been granted for this version to appear in e-Publications@Marquette. Elsevier does not grant permission for this article to be further copied/distributed or hosted elsewhere without the express permission from Elsevier.] 
results did not compare any better with the interaction effect studies. Instead, using comparably arousing stimuli, we found equivalent enhancement of retention for all four stimulus categories, rather than selectivity for high arousal stimuli. The results therefore suggest a rather generalized effect of post-task arousal on consolidation of memoranda occurring soon before the arousal induction. Notably, however, the current study does not address the suggestion that task or situation novelty can generally produce better effects of postlearning modulation treatments (Okuda et al., 2004); a study familiarizing participants with the task and situation over multiple sessions would be needed to replicate and test that suggestion, which was demonstrated in rats.

Although generally comparable in method, there are still differences between studies that might prohibit clear comparisons. First, the previous studies either solely used recall (Cahill et al., 2003) or found group differences in recall but not in recognition, which may have been due to less than optimal parameters in the recognition tests (Buchanan \& Lovallo, 2001; Liu et al., 2008). However, the inherent disadvantage of incidental learning tasks is that recall performance tends to be quite low, particularly after a long delay. Indeed, the recall performance in the study from Liu and colleagues averaged between two and four pictures (out of 75) across conditions, while the study from Buchanan and Lovallo employed 60 stimuli, yielding an average of about 10 pictures recalled. In a smaller stimulus set of 21 slides, Cahill et al. (2003) found an approximate average recall of $45 \%$. This is not to imply that the low recall performance in some studies invalidates the results. Rather it highlights that the effects in such studies reflects only the most memorable stimuli. Instead, the present study utilized only recognition testing because pilot tests showed similar floor effects in recall, after which recall testing was abandoned. Alternately, to prevent ceiling effects in recognition tests, difficult parameters were used (i.e., a large distracter ratio). As such, performances were much better than in recall and were reflective of retention across the entire stimulus set, rather than of a small subset of the items. Moreover, given that the present study employed word stimuli, recognition testing may have been less challenging than with picture stimuli, where true "foils" are difficult to generate for recognition testing. On the other hand, picture stimuli include more

[Neurobiology of Learning and Memory, Vol 92, No. 1 (July, 2009): pg70-79. DOI. This article is @ Elsevier and permission has been granted for this version to appear in e-Publications@Marquette. Elsevier does not grant permission for this article to be further copied/distributed or hosted elsewhere without the express permission from Elsevier.] 
information than do word stimuli, and may therefore be easier to remember.

The previous point raises a second issue. The studies supporting arousal interaction effects all used pictorial stimuli. All of our own studies, including the present one, employed words, rather than pictures as stimuli. Although this difference might underlie the differential effects, other studies that showed comparable generalized effects rather than interaction effects also used emotive pictorial stimuli (e.g., Abercrombie et al., 2003; Maheu et al., 2004). Therefore, further study is needed to better address this question.

\subsection{Arousal predisposition}

The second goal of the current study was to investigate the influence of individual differences in memory modulation. Three factors that have each been shown to relate to arousal response were investigated. First, predisposition toward arousal led to greater arousal-induced memory enhancement, as hypothesized. Highly arousal-predisposed individuals experienced arousing stimuli as more arousing than did those who were less "arousable." Additionally, they tended to have a greater subjective response to the post-learning arousing film clip than their less predisposed counterparts. This was consistent with the literature on the APS, showing that highly predisposed individuals have greater subjective and physiological responses to arousing stimuli (Coren \& Mah, 1993). As such, they experienced greater benefit of arousal on memory consolidation. Although there are any number of factors that might underlie arousal predisposition that warrant further study, the current results suggest that predisposition toward arousal might be an important factor to consider in studies of emotional memory and memory modulation.

\subsection{Suppression}

The second factor investigated was an emotion regulation strategy termed suppression (Gross, 1998b). The current study demonstrated different experiences of the stimuli and situation in suppressors. They rated negative high arousal words as more arousing, but they rated positive low arousal words as less arousing than their low suppression counterparts. Additionally, they rated their own arousal state as lower than low suppressors in the control

[Neurobiology of Learning and Memory, Vol 92, No. 1 (July, 2009): pg70-79. DOI. This article is @ Elsevier and permission has been granted for this version to appear in e-Publications@Marquette. Elsevier does not grant permission for this article to be further copied/distributed or hosted elsewhere without the express permission from Elsevier.] 
condition, but their state increased just as much as low suppressors' did after the arousal induction. The same pattern was observed with mood. The stimulus rating suggested that suppressors found negative, highly arousing stimuli more threatening than did low suppressors. The remainder of the rating data were comparable to what has been reported in previous studies with emotive stimuli (Egloff et al., 2006; Gross \& John, 2003; Gross \& Levenson, 1993, 1997; Richards \& Gross, $\underline{2000})$.

Previous studies have generally shown that suppression leads to reduced retrieval of high arousing, and in some cases low arousing, stimuli after short-term retention tests, in the absence of differences relative to the subjective experience of the stimuli (Bonanno et al., 2004; Dillon et al., 2007; Egloff et al., 2006; Richards, 2004; Richards \& Gross, 1999, 2000). Our previous study (Nielson et al., submitted for publication), however showed that while there were no subjective differences in the experience of the stimuli, retention testing delayed by 1 -week led to no memory reduction in suppression. The current results, also utilizing a long-term test, are consistent with our previous study. We suggest that the differences in retention between short- and long-term studies is due to the resolution of arousal and the allowance for the process of memory consolidation than can occur when testing is delayed. That is, retention can be impaired by arousal when measured in the short-term (Kleinsmith \& Kaplan, 1963; Revelle \& Loftus, 1992; Torras-Garcia et al., 1997; Walker, 1958), but after a lengthy delay, the arousal resolves and memory consolidation, modulated by the arousal, occurs (cf. McGaugh, 2000, 2004). Thus, although suppressors experience increased arousal during learning with emotive stimuli that can impair short-term retrieval (Bonanno et al., 2004; Egloff et al., 2006; Richards \& Gross, 1999, 2000, 2006), long-term retrieval is not necessarily impaired due to the protective longer term effects of arousal on memory consolidation. Future studies with other types of tasks would be valuable in fully evaluating the effects of suppression on memory retention.

\subsection{Reappraisal}

Finally, the current study also demonstrated that the use of the emotional regulation strategy termed reappraisal (Gross, 1998b) led to reduced susceptibility to memory modulation by arousal. These

[Neurobiology of Learning and Memory, Vol 92, No. 1 (July, 2009): pg70-79. DOI. This article is @ Elsevier and permission has been granted for this version to appear in e-Publications@Marquette. Elsevier does not grant permission for this article to be further copied/distributed or hosted elsewhere without the express permission from Elsevier.] 
participants had reduced arousal ratings of negative, highly arousing stimuli and enhanced arousal ratings of positive low arousal stimuli. Mood and arousal state ratings were not influenced by reappraisal in this study. However, high reappraisers failed to show the enhancement of long-term memory by arousal induction following learning that those who endorsed low use of reappraisal demonstrated. These results support and extend our previous study (Nielson et al., submitted for publication) that showed better long-term retrieval (without the post-learning modulation manipulation) for these words in low reappraisers. However, the current results contrast with previous studies, which used short-term retention tests, and found either no effects of reappraisal on memory (Egloff et al., 2006; Richards \& Gross, 1999) or enhanced retrieval in reappraisal (Dillon et al., 2007; Richards \& Gross, 2000).

Although reappraisal did not influence subjective arousal response to the manipulation, the current results suggest that the intent of reappraisers to interpret the emotional stimulus in a less emotive way (Gross \& John, 2003) may have lessened arousal response, and therefore, reduced memory modulation. That is, reappraisal likely neutralized the emotional impact of the arousing stimuli (Richards, 2004), thereby reducing their advantage in longterm memory. Importantly, previous studies have suggested that in response to arousing stimuli, reappraisers experience non-significant reductions in sympathetic nervous system response to arousing stimuli (Egloff et al., 2006; Gross, 1998a; Gross \& John, 2003; Richards \& Gross, 2000), but significant reductions in amygdala activity (Goldin et al., 2008; Ochsner et al., 2004). Amygdala activation is a principal component of arousal-induced memory modulation (McGaugh, 2004). Thus, while reappraisal may afford effective control in dealing with emotive situations, the adaptive function of emotion in memory to "highlight" emotive events for better retention (e.g., McGaugh, 1990) may be diminished by disengaging from their emotive value.

Memory modulation studies and attempts to utilize memory modulation as a practical intervention may need to take into account individual differences that affect arousal responsiveness in interpreting results. Our findings that reappraisers report being less aroused in potentially emotion-eliciting situations and do not evidence related improvements in memory that commonly occur as a function of

[Neurobiology of Learning and Memory, Vol 92, No. 1 (July, 2009): pg70-79. DOI. This article is (C) Elsevier and permission has been granted for this version to appear in e-Publications@Marquette. Elsevier does not grant permission for this article to be further copied/distributed or hosted elsewhere without the express permission from Elsevier.] 
arousal can be thought of as a "manipulation check" on the emotion regulation strategy of reappraisal. That is, our findings provide further evidence that reappraisal lessens the degree to which emotions are experienced in potentially emotion-eliciting situations, or, at minimum, that reappraisal works as a way to lessen arousal in potentially emotion-eliciting situations. Therefore, reappraisal can be recommended as an emotion regulation strategy when one's objective is to lessen the experience of emotion, and reappraisal is not ideal for situations where lessening the experience of emotion is not adaptive.

\section{Conclusions}

Emotional arousal, induced after a word-rating task, significantly enhanced 1-week delayed retrieval and the effect did not interact with the inherent arousal or valence quality of the words or with their serial position in the list. This finding contrasts with a few studies suggesting that arousal interacts with arousal state at encoding and with the qualitative aspects of the stimuli (Cahill et al., 2003; Liu et al., 2008), instead showing that arousal induced after learning words enhances memory consolidation generally, spanning a lengthy task without preference for material type or position. Thus, the results support the use of arousal in memory intervention strategies.

However, the results also showed that predisposition toward responding to arousal and the tendency to regulate emotion using reappraisal of emotion significantly influenced response to arousalinduced memory modulation. Specifically, those who were particularly susceptible to arousal response were also responsive to memory modulation, showing significantly enhanced long-term retention. In contrast, those with low susceptibility did not show comparable enhancement. Similarly, those who endorse regulating their emotions using reappraisal, which can decrease arousal response, failed to show a memory benefit from arousal induced after learning. The results suggest that individual differences that are known to influence response to arousal can have meaningful effects on the effectiveness of memory modulation strategies.

\section{Acknowledgments}

The invaluable assistance of the following individuals to the completion of this project is gratefully acknowledged: Alison Althaus, Clare Tyson

[Neurobiology of Learning and Memory, Vol 92, No. 1 (July, 2009): pg70-79. DOI. This article is @ Elsevier and permission has been granted for this version to appear in e-Publications@Marquette. Elsevier does not grant permission for this article to be further copied/distributed or hosted elsewhere without the express permission from Elsevier.] 
NOT THE PUBLISHED VERSION; this is the author's final, peer-reviewed manuscript. The published version may be accessed by following the link in the citation at the bottom of the page.

Bingham, Annie Boyd, Maeghan Carpenter, Karla Felske, Carolyn Freitag, Josh Koyen, Lauren McGurn, Theresa Niles, Rebecca Phillips, Anna Pistas, Mark Powless, Shivani Raniga, Julie Riederer, Michelle Schoenleber, Maureen Schrock, and Cal Stoffel. This work was partially supported by Marquette University.

\section{References}

H.C. Abercrombie, N.H. Kalin, M.E. Thurow, M.A. Rosenkranz, R.J. Davidson Cortisol variation in humans affects memory for emotionally laden and neutral information Behavioral Neuroscience, 117 (2003), pp. 505-516

R. Adolphs, D. Tranel, T.W. Buchanan Amygdala damage impairs emotional memory for gist but not details of complex stimuli Nature Neuroscience, 8 (4) (2005), pp. 512518

T.M. Blake, C.K. Varnhagen, M.B. Parent Emotionally arousing pictures increase blood glucose levels and enhance recall Neurobiology of Learning and Memory, 75 (2001), pp. 262-273

N.J. Bohannon Flashbulbe memories for the space shuttle disaster: A tale of two theories Cognition, 29 (1988), pp. 179-196

G.A. Bonanno, A. Papa, K. Lalande, M. Westphal, K. Coifman The importance of being flexible: The ability to both enhance and suppress emotional expression predicts long-term adjustment Psychological Science, 15 (7) (2004), pp. 482-487[]ournal; Peer Reviewed Journal]

Bradley, M.M., \& Lang, P.J. (1999). Affective norms for English words (ANEW): Instruction manual and affective ratings.

Technical Report C-1, The Center for Research in Psychophysiology, University of Florida.

T.W. Buchanan, W.R. Lovallo Enhanced memory for emotional material following stress-level cortisol

[Neurobiology of Learning and Memory, Vol 92, No. 1 (July, 2009): pg70-79. DOI. This article is @ Elsevier and permission has been granted for this version to appear in e-Publications@Marquette. Elsevier does not grant permission for this article to be further copied/distributed or hosted elsewhere without the express permission from Elsevier.] 
NOT THE PUBLISHED VERSION; this is the author's final, peer-reviewed manuscript. The published version may be accessed by following the link in the citation at the bottom of the page.

treatment in humans Psychoneuroendocrinology, 26 (2001), pp. 307-317

N. Burgess, G.J. Hitch Memory for serial order: A network model of the phonological loop and its timing Psychological Review, 106 (3) (1999), pp. 551-581[Journal; Peer Reviewed Journal]

L. Cahill, M.T. Alkire Epinephrine enhancement of human memory consolidation: Interaction with arousal at encoding Neurobiology of Learning and Memory, 79 (2) (2003), pp. 194-198

\section{Cahill, L. Gorski, K. Le Enhanced human memory} consolidation with post-learning stress: Interaction with the degree of arousal at encoding Learning and Memory, 10 (4) (2003), pp. 270-274

L. Cahill, B. Prins, M. Weber, J.L. McGaugh Beta-adrenergic activation and memory for emotional events Nature, 371 (1994), pp. 702-704

T. Canli, Z. Zhao, J. Brewer, J.D. Gabrieli, L. Cahill Eventrelated activation in the human amygdala associates with later memory for individual emotional experience Journal of Neuroscience, 20 (19) (2000), p. RC99

I.M. Colrain, G.L. Mangan, O.L. Pellett, T.C. Bates Effects of post-learning smoking on memory consolidation Psychopharmacology, 108 (1992), pp. 448-451

M. Conway, S. Anderson, S. Larsen, F. Steen, C. Donnelly, M. McDaniel, et al. The formation of flashbulb memories Memory and Cognition, 22 (3) (1994), pp. 326-343

S. Coren Prediction of insomnia from arousability predisposition scores: Scale development and crossvalidation Behaviour Research and Therapy, 26 (5) (1988), pp. 415-420[Journal; Peer Reviewed Journal] 
NOT THE PUBLISHED VERSION; this is the author's final, peer-reviewed manuscript. The published version may be accessed by following the link in the citation at the bottom of the page.

S. Coren The arousal predisposition scale: Normative data Bulletin of the Psychonomic Society, 28 (6) (1990), pp. 551552[Journal; Peer-Reviewed Status-Unknown]

S. Coren Arousal predisposition as a predictor of antisocial and delinquent behavior Personality and Individual Differences, 27 (5) (1999), pp. 815-820[Journal; Peer Reviewed Journal]

S. Coren, D.J. Aks Prediction of task-related arousal under conditions of environmental distraction Journal of Applied Social Psychology, 21 (3) (1991), pp. 189-197[Journal; Peer Reviewed Journal]

S. Coren, K.B. Mah Prediction of physiological arousability: A validation of the arousal predisposition scale Behaviour Research and Therapy, 31 (1993), pp. 215-219

R.G. Crowder Visual and auditory memory J.F. Kavanagh, I.G. Mattingly (Eds.), Language by ear and by eye: The relationship between speech and reading, Maschusetts Inst. of Technology P. Massachusetts Inst. of Technology, Oxford, England (1972) [P Print]

D.A. Czech, K.A. Nielson, K.K. Laubmeier Chronic administration of propranolol impairs Morris water maze retention in the mouse Neurobiology of Learning and Memory, 74 (2000), pp. 17-26

S.S. Dickerson, M.E. Kemeny Acute stressors and cortisol responses: A theoretical integration and synthesis of laboratory research Psychological Bulletin, 130 (3) (2004), pp. 355-391

D.G. Dillon, M. Ritchey, B.D. Johnson, K.S. LaBar Dissociable effects of conscious emotion regulation strategies on explicit and implicit memory Emotion, 7 (2) (2007), pp. 354365[Journal; Peer Reviewed Journal]

[Neurobiology of Learning and Memory, Vol 92, No. 1 (July, 2009): pg70-79. DOI. This article is @ Elsevier and permission has been granted for this version to appear in e-Publications@Marquette. Elsevier does not grant permission for this article to be further copied/distributed or hosted elsewhere without the express permission from Elsevier.] 
NOT THE PUBLISHED VERSION; this is the author's final, peer-reviewed manuscript. The published version may be accessed by following the link in the citation at the bottom of the page.

F. Dolcos, R. Cabeza Event-related potentials of emotional memory: Encoding pleasant, unpleasant, and neutral pictures Cognitive, Affective \& Behavioral Neuroscience, 2 (3) (2002), pp. 252-263[Journal; Peer Reviewed Journal]

B. Egloff, S.C. Schmukle, L.R. Burns, A. Schwerdtfeger Spontaneous emotion regulation during evaluated speaking tasks: Associations with negative affect, anxiety expression, memory, and physiological responding Emotion, 6 (3) (2006), pp. 356-366[Journal; Peer Reviewed Journal]

H. Garavan, J.C. Pendergrass, T.J. Ross, E.A. Stein, R.C. Risinger Amygdala response to both positively and negatively valenced stimuli Neuroreport: For Rapid Communication of Neuroscience Research, 12 (12) (2001), pp. 2779-2783[Journal; Peer Reviewed Journal]

P.E. Gold, R. McCarty Plasma catecholamines: Changes after footshock and seizure-producing frontal cortex stimulation Behavioral and Neural Biology, 31 (1981), pp. 247260

P.E. Gold, J.L. McGaugh A single-trace, two-process view of memory storage processes D. Deutsch, J.A. Deutsch (Eds.), Short-term memory, Academic Press, New York (1975), pp. 355-378

P.E. Gold, R. van Buskirk Facilitation of time-dependent memory processes with posttrial epinephrine injections Behavioral Biology, 13 (1975), pp. 145-153

P.R. Goldin, K. McRae, W. Ramel, J.J. Gross The neural bases of emotion regulation: Reappraisal and suppression of negative emotion Biological Psychiatry, 63 (6) (2008), pp. 577-586[Journal; Peer Reviewed Journal] 
K.L. Gratz, L. Roemer Multidimensional assessment of emotion regulation and dysregulation: Development, factor structure, and initial validation of the difficulties in emotion regulation scale Journal of Psychopathology and Behavioral Assessment, 26 (1) (2004), pp. 41-54[Journal; Peer Reviewed Journal]

J.J. Gross Antecedent- and response-focused emotion regulation: Divergent consequences for experience, expression, and physiology Journal of Personality and Social Psychology, 74 (1) (1998), pp. 224-237[Journal; Peer Reviewed Journal]

\section{J.J. Gross The emerging field of emotion regulation: An} integrative review Review of General Psychology, 2 (3) (1998), pp. 271-299[Journal; Peer Reviewed Journal]

J.J. Gross Emotion regulation: Affective, cognitive, and social consequences Psychophysiology, 39 (3) (2002), pp. 281-291[Journal; Peer Reviewed Journal]

J.J. Gross, O.P. John Individual differences in two emotional regulations processes: Implications for affect, relationships and well-being Journal of Personality and Social Psychology, 85 (2) (2003), pp. 348-362

\section{J.J. Gross, R.W. Levenson Emotional suppression:}

Physiology, self-report, and expressive behavior Journal of Personality and Social Psychology, 64 (6) (1993), pp. 970986[Journal; Peer Reviewed Journal]

J.J. Gross, R.W. Levenson Hiding feelings: The acute effects of inhibiting negative and positive emotion Journal of Abnormal Psychology, 106 (1) (1997), pp. 95-103[Journal; Peer Reviewed Journal]

S.C. Guy, L. Cahill The role of overt rehearsal in enhanced conscious memory for emotional events Consciousness and Cognition, 8 (1999), pp. 114-122 
NOT THE PUBLISHED VERSION; this is the author's final, peer-reviewed manuscript. The published version may be accessed by following the link in the citation at the bottom of the page.

S. Hamann, H. Mao Positive and negative emotional verbal stimuli elicit activity in the left amygdala Neuroreport: For Rapid Communication of Neuroscience Research, 13 (1) (2002), pp. 15-19[Journal; Peer Reviewed Journal]

E.A. Kensinger, S. Corkin Two routes to emotional memory: Distinct neural processes for valence and arousal Proceedings of the National Academy of Sciences of the United States of America, 101 (9) (2004), pp. 3310-3315

E.C. Kerfoot, E.A. Chattillion, C.L. Williams Functional interactions between the nucleus tractus solitarius (NTS) and nucleus accumbens shell in modulating memory for arousing experiences Neurobiology of Learning and Memory, 89 (1) (2008), pp. 47-60[Journal; Peer Reviewed Journal]

L.J. Kleinsmith, S. Kaplan Paired-associate learning as a function of arousal and interpolated interval Journal of Experimental Psychology, 65 (2) (1963), pp. 190-193[Journal; Peer Reviewed Journal]

K.S. LaBar, R. Cabeza Cognitive neuroscience of emotional memory Nature Reviews Neuroscience, 7 (1) (2006), pp. 5464[Journal; Peer Reviewed Journal]

D.L.J. Liu, S. Graham, M. Zorawski Enhanced selective memory consolidation following post-learning pleasant and aversive arousal Neurobiology of Learning and Memory, 89 (1) (2008), pp. 36-46[Journal; Peer Reviewed Journal]

R.B. Livingston Reinforcement G. Quarton, T. Melnechuk, F. Schmitt (Eds.), The neurosciences: A study program, Rockefeller Press, New York (1967), pp. 514-576

S.J. Lupien, C.W. Wilkinson, S. Briere, C. Menard, N.M. Ng Ying Kin, N.P. Nair The modulatory effects of corticosteroids on

[Neurobiology of Learning and Memory, Vol 92, No. 1 (July, 2009): pg70-79. DOI. This article is @ Elsevier and permission has been granted for this version to appear in e-Publications@Marquette. Elsevier does not grant permission for this article to be further copied/distributed or hosted elsewhere without the express permission from Elsevier.] 
NOT THE PUBLISHED VERSION; this is the author's final, peer-reviewed manuscript. The published version may be accessed by following the link in the citation at the bottom of the page.

cognition: Studies in young human populations

Psychoneuroendocrinology, 27 (3) (2002), pp. 401-416

F.S. Maheu, R. Joober, S. Beaulieu, S.J. Lupien Differential effects of adrenergic and corticosteroid hormonal systems on human short- and long-term declarative memory for emotionally arousing material Behavioral Neuroscience, 118 (2) (2004), pp. 420-428

C.A. Manning, M. Parsons, P.E. Gold Anterograde and retrograde enhancement of 24-h memory by glucose in elderly humans Behavioral and Neural Biology, 58 (1992), pp. 125-130

J.L. McGaugh Time-dependent processes in memory storage Science, 153 (1966), pp. 1351-1358

J.L. McGaugh Significance and remembrance: The role of neuromodulatory systems Psychological Science, 1 (1990), pp. $15-25$

J.L. McGaugh Memory - A century of consolidation Science, 287 (14 January) (2000), pp. 248-251

J.L. McGaugh The amygdala modulates the consolidation of memories of emotionally arousing experiences Annual Review of Neuroscience, 27 (2004), pp. 1-28[Journal; Peer Reviewed Journal]

Z. Merali, J. McIntosh, P. Kent, D. Michaud, H. Anisman Aversive and appetitive events evoke the release of corticotropin-releasing hormone and bombesin-like peptides at the central nucleus of the amygdala Journal of Neuroscience, 18 (12) (1998), pp. 4758-4766

T. Miyashita, C.L. Williams Peripheral arousal-related hormones modulate norepinephrine release in the hippocampus via influences on brainstem nuclei Behavioural Brain Research, 153 (1) (2004), pp. 87-95 
G.E. Müller, A. Pilzecker Experimentelle beitrage zur lehre vom gedachtnis [Experimental contributions in learning and memory] Zeitschrift für Psychologie Erganzungsband, 1 (1900), pp. 1-288

K.A. Nielson, T. Bryant The effects of non-contingent extrinsic and intrinsic rewards on memory consolidation Neurobiology of Learning and Memory, 84 (2005), pp. 42-48

K.A. Nielson, D.A. Czech, K.K. Laubmeier Chronic administration of propranolol impairs inhibitory avoidance retention in the mouse Neurobiology of Learning and Memory, 71 (1999), pp. 248-257

K.A. Nielson, R.A. Jensen Beta-adrenergic receptor antagonist antihypertensive medications impair arousalinduced modulation of working memory in elderly humans Behavioral and Neural Biology, 62 (1994), pp. 190-200

Nielson, K. A., Lorber, W. \& Riederer, J. (submitted for publication). The role of emotion regulation in interpreting and remembering emotionally provocative words.

K.A. Nielson, M. Powless Positive and negative sources of emotional arousal enhance long-term word-list retention when induced as long as thirty minutes after learning Neurobiology of Learning and Memory, 88 (2007), pp. 40-47

K.A. Nielson, R.C. Radtke, R.A. Jensen Arousal-induced modulation of memory storage processes in humans Neurobiology of Learning and Memory, 66 (1996), pp. 133-142

K.A. Nielson, D. Yee, K.I. Erickson Memory enhancement by a semantically unrelated emotional arousal source induced after learning Neurobiology of Learning and Memory, 84 (2005), pp. 49-56 
NOT THE PUBLISHED VERSION; this is the author's final, peer-reviewed manuscript. The published version may be accessed by following the link in the citation at the bottom of the page.

K.N. Ochsner, K. Knierim, D.H. Ludlow, J. Hanelin, T.

Ramachandran, G. Glover, et al. Reflecting upon feelings: An fMRI study of neural systems supporting the attribution of emotion to self and other Journal of Cognitive Neuroscience, 16 (10) (2004), pp. 1746-1772[Journal; Peer Reviewed Journal]

S. Okuda, B. Roozendaal, J.L. McGaugh Glucocorticoid effects on object recognition memory require training-associated emotional arousal Proceedings of the National Academy of Sciences of the United States of America, 101 (3) (2004), pp. 853-858

P.V. Piazza, M. Le Moal Glucocorticoids as a biological substrate of reward: Physiological and pathophysiological implications Brain Research - Brain Research Reviews, 25 (3) (1997), pp. 359-372

W. Revelle, D.A. Loftus The implications of arousal effects for the study of affect and memory S. Christianson (Ed.), The handbook of emotion and memory, Lawrence Erlbaum Assoc, Hillsdale (1992), pp. 113-150

J.M. Richards The cognitive consequences of concealing feelings Current Directions in Psychological Science, 13 (4) (2004), pp. 131-134[Journal; Peer Reviewed Journal]

J.M. Richards, J.J. Gross Composure at any cost? The cognitive consequences of emotion suppression Personality and Social Psychology Bulletin, 25 (8) (1999), pp. 1033-1044[Journal; Peer Reviewed Journal]

J.M. Richards, J.J. Gross Emotion regulation and memory: The cognitive costs of keeping one's cool Journal of Personality and Social Psychology, 79 (3) (2000), pp. 410424[Journal; Peer Reviewed Journal]

[Neurobiology of Learning and Memory, Vol 92, No. 1 (July, 2009): pg70-79. DOI. This article is @ Elsevier and permission has been granted for this version to appear in e-Publications@Marquette. Elsevier does not grant permission for this article to be further copied/distributed or hosted elsewhere without the express permission from Elsevier.] 
NOT THE PUBLISHED VERSION; this is the author's final, peer-reviewed manuscript. The published version may be accessed by following the link in the citation at the bottom of the page.

J.M. Richards, J.J. Gross Personality and emotional memory: How regulating emotion impairs memory for emotional events Journal of Research in Personality, 40 (5) (2006), pp. 631-651[Journal; Peer Reviewed Journal]

S.M. Southwick, M. Davis, B. Horner, L. Cahill, C.A. Morgan III, P.E. Gold, et al. Relationship of enhanced norephinphrine activity during memory consolidation to enhanced longterm memory in humans American Journal of Psychiatry, 159 (2002), pp. 1420-1422

L.R. Squire Mechanisms of memory Science, 332 (1986), pp. 1612-1619

M. Torras-Garcia, I. Portell-Cortes, D. Costa-Miserachs, I. Morgado-Bernal Long-term memory modulation by posttraining epinephrine in rats differential effects depending on the basic learning capacity Behavioral Neuroscience, 111 (1997), pp. 301-308

A.H. van Stegeren, W. Everaerd, L. Cahill, J.L. McGaugh, L.J.G. Gooren Memory for emotional events: Differential effects of centrally versus peripherally acting beta-blocking agents Psychopharmacology, 138 (1998), pp. 305-310

\section{E.L. Walker Action decrement and its relation to learning Psychological Review, 65 (1958), pp. 129-142}

R. Yerkes, J. Dodson The relation of strength of stimulus to rapidity of habit-formation Journal of Comparative Neurology and Psychology, 18 (1908), pp. 459-482 